\title{
KEEFEKTIFAN MEDIA KOMIK STRIP TERHADAP PENINGKATAN KEMAMPUAN MENULIS KARANGAN SEDERHANA SISWA KELAS III SDN KEDUNGMUNDU SEMARANG
}

\author{
Dwi Sabti Pratiwi \\ pratiwidwi37@gmail.com \\ Universitas PGRI Semarang
}

\begin{abstract}
ABSTRAK
Penelitian ini bertujuan untuk mengetahui keefektifan media komik strip terhadap kemampuan menulis karangan sederhana siswa kelas III SDN Kedungmundu Semarang. Penelitian ini adalah penelitian kuantitatif dengan desain Pre-Experimental dengan jenis One GroupPretest-Posttest. Teknik sampel yang digunakan adalah nonprobability sampling dengan jenis sampling jenuh. Populasi dalam penelitian ini adalah seluruh siswa kelas III SDN Kedungmundu Semarang tahun ajaran 2017/2018. Hasil dari penelitian ini menunjukkan bahwa media komik strip efektif terhadap kemampuan menulis karangan sederhana yang dibuktikan dengan $\mathrm{t}_{\text {hitung }}=4,482>\mathrm{t}_{\text {tabel }}=1,697$.
\end{abstract}

Kata kunci : Media Komik Strip. Kemampuan Menulis Karangan Sederhana

\section{PENDAHULUAN}

Pembelajaran adalah usahausaha yang terencana dalam memanipulasi sumber-sumber belajar agar terjadi proses belajar dalam diri siswa (Arief Sadiman,1984:7). Sumber daya pendidikan adalah segala sesuatu yang dipergunakan dalam penyelenggaraan pendidikan yang meliputi tenaga kependidikan, masyarakat, dana, sarana, dan prasarana, hal ini sejalan dengan Undang-undang No 20 Tahun 2003 pasal 1 ayat 23. Dalam kemampuan menulis karangan sederhana siswa kelas III rata-rata masih di bawah KKM padahal menurut KKM harusnya diatas 73 . Sama halnya di kelas III SDN Kedungmundu Semarang.

Berdasarkan hasil observasi di SDN Kedungmundu Semarang dapat diketahui bahwa kompetensi dasar 8.1 Menulis karangan sederhana berdasarkan gambar menggunakan pilihan kata dan kalimat yang tepat dengan memperhatikan penggunaan ejaan, huruf kapital, dan tanda titik masih rendah. Beberapa masalah yang menjadi kendala dalam belajar 
dimungkinkan: (1) kemampuan menulis karangan sederhana siswa rendah dikarenakan guru menggunakan media yang kurang menarik perhatian siswa; kemampuan menulis karangan sederhana siswa masih rendah karena guru masih menggunakan metode ceramah, tanya jawab, dan penugasan; (3) kemampuan menulis karangan sederhana siswa rendah karena guru belum menggunakan model pembelajaran yang kooperatif;

(4) kemampuan menulis karangan sederhana rendah karena sebagian siswa ada yang aktif dan tidak aktif dalam pembelajaran.

Berdasarkan permasalahan tersebut diperlukan solusi-solusi dalam mencapai kemampuan menulis karangan sederhana yaitu berupa penggunaan media komik strip. Sehingga pembelajaran yang dilaksanakan dapat menjadi lebih efektif dan menarik. Dalam memilih media pembelajaran harus disesuaikan dengan pembelajaran yang akan digunakan untuk memcapai kemampuan menulis karangan sederhana pada siswa. Media komik strip dapat diterapkan dalam proses belajar untuk mencapai tujuan belajar.

Dalam penelitian yang dilakukan oleh Alfiyah Nurul A'zizah dengan judul Peningkatan Keterampilan Menulis Karangan Dengan Penerapan Metode Permainan Susun Gambar dalam Pembelajaran Bahasa Indonesia Kelas III SD Muhammadiyah 12 Pamulang Tanggerang mencapai kategori yang baik. Dari analisis hasil-hasil penelitian yang sejenis belum ada judul yang meneliti tentang media komik strip.

Berdasarkan latar belakang di atas, maka peneliti melakukan penelitian dengan judul "Keefektifan Media Komik Strip terhadap Peningkatan Kemampuan Menulis Karangan Sederhana Siswa Kelas III SDN Kedungmundu Semarang”. Melalui kajian yang mendalam terhadap penelitian, belum ditemukan kajian yang membahas masalah tersebut. Dengan demikian, penelitian ini sangat penting dilakukan. 


\section{METODE}

Penelitian ini adalah penelitian kuantitatif dengan desain PreExperimental dengan jenis One Group Pretest-Posttest. Teknik sampling yang digunakan dalam penelitian ini adalah teknik sampling jenuh dengan populasi dalam penelitian ini adalah seluruh siswa kelas III SDN Kedungmundu Semarang. Data diperoleh dari hasil tes awal dan tes akhir. Teknik pengumpulan data yang digunakan adalah observasi, dokumentasi, dan tes. Analisis data dalam penelitian ini adalah uji normalitas (Liliefors) dan uji $t$-test.

\section{PEMBAHASAN}

Penelitian diawali dengan pemberian soal tes awalatau sebelum siswa mendapatkan perlakuan dengan media komik strip. Diakhir pembelajaran dilakukan tes akhiratau siswa telah mendapatkan perlakuan pembelajaran media komik strip. Berdasarkan hasil tes awal dan tes akhir didapatkan nilai hasil belajar seperti tabel berikut

Tabel 1. Data kemampuan menulis karangan sederhana tes awal dantes

\begin{tabular}{lc} 
akhir \\
\hline Keterangan $\quad$ Tes awalTes akhir
\end{tabular}

\begin{tabular}{lll}
\hline Nilai Tertinggi & 80 & 85 \\
Nilai Terendah & 25 & 50 \\
Rata-Rata & 6071,57 &
\end{tabular}

$\begin{array}{lll}\text { Siswa tuntas } & 7 & 18\end{array}$

Dari hasil tabel di atas media komik strip efektif terhadap peningkatan kemampuan menulis karangan sederhana siswa kelas III SDN Kedungmundu Semarang. Hal ini diperkuat dengan hasil uji normalitas awal yang diperoleh dari $\mathrm{L}_{0} 0,1238$ dengan taraf nyata $5 \%$ $(0,05)$ dan $\mathrm{L}_{\text {tabel }}$ 0,1499. Berdasarkan kriteria $\mathrm{L}_{0} \leq \mathrm{L}_{\text {tabel }}$ diperoleh $0,1238 \leq$ 0,1499. Maka, $\mathrm{H}_{0}$ diterima sehingga dapat disimpulkan sampel berasal dari distribusi normal. Sedangkan uji normalitas akhir diperoleh $\mathrm{L}_{0} 0,1160$ dengan taraf nyata $5 \%(0,05)$ dan $\mathrm{L}_{\text {tabel }}$ 0,1499. Berdasarkan kriteria $\mathrm{L}_{0}$ $\leq \mathrm{L}_{\text {tabel }}$ diperoleh $0,1160 \leq 0,1499$. Maka, $\mathrm{H}_{0}$ diterima sehingga dapat disimpulkan sampel berasal dari distribusi normal. 
Selain itu berdasarkan hasil uji t-test diperoleh $t_{\text {hitung }}$ sebesar 4.48228 dan $\mathrm{t}_{\text {tabel }}$ diperoleh dari $\mathrm{db}=$ $(\mathrm{N}-1)=35-1=34$ taraf signifikan 5\% $(0,05) \quad$ sebesar 2,145. Jadi $\mathrm{t}_{\text {hitung }} 4.48228 \geq \mathrm{t}_{\text {tabel }} 2,145$. Karena $\mathrm{t}_{\text {hitung }} \geq \mathrm{t}_{\text {tabel, }}$ maka $\mathrm{H}_{0}$ ditolak. Artinya rataan hasil belajar membaca intensif siswa sebelum dan sesudah perlakuan tidak sama/meningkat.

\section{SIMPULAN}

Berdasarkan hasil penelitian dan pembahasan, maka dapat disimpulkan bahwa media komik strip efektif terhadap peningkatan kemampuan menulis karangan sederhana siswa kelas III SDN Kedungmundu Semarang yang ditunjukkan dari hasil pengujian: Media komik strip efektif terhadap peningkatan kemampuan menulis karangan sederhana. Hal ini ditunjukan dengan hasil perhitungan $\mathrm{t}_{\text {hitung }}=4,48228 \geq \mathrm{t}_{\text {tabel }} 2,145$, yang berarti nilai KKM siswa tercapai. Berdasarkan perhitungan tersebut maka $\mathrm{H}_{0}$ ditolak karena $\mathrm{t}_{\text {hitung }} \geq \mathrm{t}_{\text {tabel. }}$ Apabila $\mathrm{H}_{0}$ dapat diartikan bahwa rataan kemampuan menulis karangan siswa sebelum dan sesudah diberikan perlakuan tidak sama atau

meningkat.

\section{DAFTAR PUSTAKA}

Esti, Ismiawati. Dr \& Faraz Umaya. Dr. Belajar Bahasa di Kelas Awal. Yogyakarta: Penerbit Ombak.

Kusumaningsih, Dewi dkk. 2013. Terampil Berbahasa Indonesia. Yogyakarta: CV. Andi Offset

LIANG GIE, THE. 2002. Terampil Mengarang. Edisi 1. Yogyakarta: Andi.

Nurgiyantoro, Burhan. 2010. Sastra Anak Pengantar Pemahaman Dunia Anak. Yogyakarta: Gadjah Mada University Press.

Nurgiyantoro, Burhan. 2001. Penilaian dalam Pengajaran Bahasa dan Sastra. Yogyakarta: BPFE Yogyakarta.

Permendikbud No 20 tahun 2003 pasal Qoqoazroqu.blogspot.com. diakses pada tanggal 18 April 2018 pukul 15.05.

Rohani, Ahmad. 1997. Media Instruksional Edukatif. Jakarta: PT RINEKA CIPTA.

Sugiyono. 2016. Metode Penelitian Pendidikan.

Bandung: ALFABETA.

Tarigan, Djago. 1995. Membina Keterampilan Menulis Paragraf dan Pengembangannya. Bandung: Angkasa 